\title{
Stereoselective glycosylation of exo-glycals by microwave-assisted Ferrier rearrangement
}

\author{
Hui-Chang Lin, ${ }^{\mathrm{a}}$ Chih-Chun Chang, ${ }^{\mathrm{a}} \mathrm{Jia}^{-Y i} \mathrm{Chen}^{\mathrm{a}}$ and Chun-Hung Lin ${ }^{\mathrm{a}, \mathrm{b}, *}$ \\ ${ }^{a}$ Institute of Biological Chemistry, Academia Sinica, No 128 Academia Road Section 2, Nan-Kang, Taipei 11529, Taiwan \\ ${ }^{\mathrm{b}}$ Institute of Biochemical Sciences, College of Life Science, National Taiwan University, Taipei 10617, Taiwan
}

Received 8 November 2004; accepted 19 November 2004

Available online 5 January 2005

\begin{abstract}
Glycosyl carbonates were shown to be efficient glycosyl donors in microwave-assisted glycosylation. In these reactions $\alpha$-glycosyl additions occurred with excellent stereoselectivity and were complete in 4-8 min with 75-92\% yield. Interestingly exo-glycals were found to have higher activity than endo-glycals and common glycosides, the reactions of which can be improved by the addition of Lewis acid to result in a higher yield and enhanced stereoselectivity.
\end{abstract}

(c) 2004 Elsevier Ltd. All rights reserved.

Glycals are unsaturated sugars with a double bond at the anomeric center. They are categorized as endo- and exo-glycals according to the double bond located inside or outside the sugar ring, respectively. endo-Glycals have been extensively investigated and numerous applications were developed for various synthetic purposes. Especially the method of 'glycal assembly', utilizing endo-glycals as both glycosyl donors and acceptors, has carried out various glycosylation reactions in an iterative fashion with minimal protecting group manipulation. ${ }^{1} \mathrm{~A}$ number of complex oligosaccharides, glycosylated natural products and tumor-associated carbohydrate antigens have been successfully prepared by Danishefsky et al. starting from endo-glycals. ${ }^{2-6}$

Furthermore, exo-glycals have been shown great promise in the synthesis of $C$-glycosides, ketoses, and ketosides, and $\mathrm{N}$-glycosides. ${ }^{7}$ In particular, we recently established an expeditious two-step method to prepare exo-glycals in a good overall yield starting from sugar lactones. ${ }^{8,9}$ The procedure is not only suitable for various monosaccharyl precursors including gluco-, galacto-, manno-, and fuco-types, but also applicable to generate exo-glycals with different substituents. ${ }^{10}$ Among them compounds 1 and $\mathbf{2}$ (Fig. 1) were found to be highly reactive in Lewis acid-catalyzed glycosylation to afford various glycosides with exclusive $\alpha$-con-

\footnotetext{
* Corresponding author. Tel.: +88622789 0110; fax: +88622651

4705; e-mail: chunhung@gate.sinica.edu.tw
}
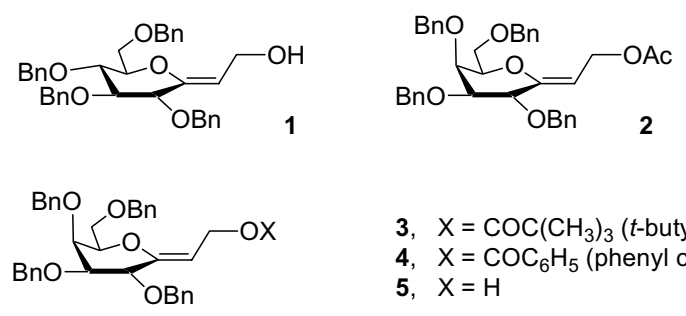

3, $\mathrm{X}=\mathrm{COC}\left(\mathrm{CH}_{3}\right)_{3}$ (t-butyl carbonate)

4, $\mathrm{X}=\mathrm{COC}_{6} \mathrm{H}_{5}$ (phenyl carbonate)

5, $X=\mathrm{H}$

Figure 1. Structures of compounds 1-5.

figuration. ${ }^{11}$ The enhanced activity was owing to allylic rearrangement, commonly known as the Ferrier reaction. In search of a better promoter for glycosidic bond formation, carbonates $\mathbf{3}$ and $\mathbf{4}$ are considered as better glycosyl donors because the decarboxylation occurs to release carbon dioxide during the heating process, as an extra driving force to increase further the reactivity. The strategy was previously used in the inter- $^{12,13}$ and intra-molecular ${ }^{14,15}$ glycosidations. The carbonate is able to serve as a good leaving group, as well as a linker to connect the donor and acceptor (in the latter case). Herein we report the microwave-induced glycosylation of exo-glycals. The microwave method was found to be superior to the traditional heating, representing a coherent conclusion with the previous reports. ${ }^{16}$ Despite a growing interest in the studies of microwave-assisted reactions in organic synthesis since $1986,{ }^{17}$ their application in carbohydrate chemistry is rather restricted. ${ }^{18-20}$ 

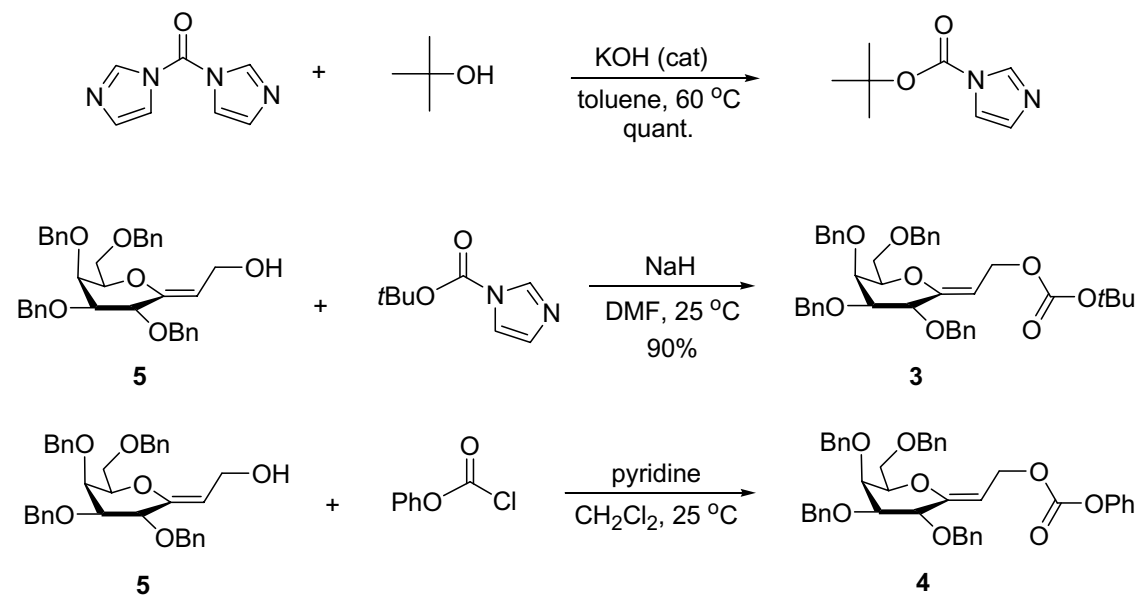

Scheme 1. Preparation of exo-glycosyl carbonates $\mathbf{3}$ and $\mathbf{4}$ as the glycosylation donors.

To prepare compounds $\mathbf{3}$ and $\mathbf{4}$ is straightforward. As shown in Scheme 1, the reaction of 1-(Z)-(2'-hydroxyethylidene)-2,3,4,6-tetra- $O$-benzyl-D-galacto-pyranoside 5 with $t$-butoxycarbonylimidazole (synthesized quantitatively by the condensation of $1,1^{\prime}$-carbonyldiimidazole and $t$-butanol $)^{21}$ in the presence of 1 equiv sodium hydride afforded the desired product 3 in $90 \%$ yield from 5. Likewise compound $\mathbf{4}$ can be synthesized by a similar coupling reaction of $\mathbf{5}$ with phenyl chloroformate. How- ever, instability made exo-glycal 4 less suitable for longterm storage and routine investigation.

The reaction of exo-glycal 3 with allyl alcohol took $20 \mathrm{~h}$ under the reflux condition in DMF to afford the desired product in $83 \%$ yield. A higher yield $(92 \%)$ with shorter reaction time (4 min) was observed by using microwave irradiation. Table 1 demonstrates the microwaveassisted glycosylations of exo-glycals $\mathbf{3}$ and $\mathbf{4}$ to produce

Table 1. Microwave-assisted glycosylation of exo-glycals 3 and $\mathbf{4}$

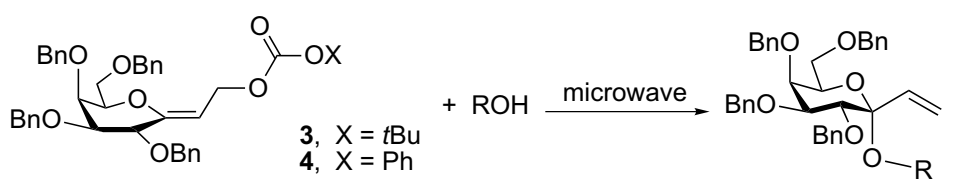

\begin{tabular}{|c|c|c|c|c|}
\hline Entry & Donor & Acceptor $(\mathrm{ROH})^{\mathrm{a}}$ & Time (min) & Product [yield (\%)] ${ }^{\mathrm{b}}$ \\
\hline $\mathrm{i}$ & 3 & $\mathrm{OH}$ & 8 & $6(90 \%)$ \\
\hline ii & 3 & & 8 & $7(85 \%)$ \\
\hline iii & 3 & & 4 & $8(87 \%)$ \\
\hline iv & 3 & & 20 & $9(75 \%)$ \\
\hline $\mathrm{v}$ & 3 & & 8 & $10(85 \%)$ \\
\hline vi & 3 & $\mathrm{OH}$ & 4 & $11(78 \%)$ \\
\hline vii & 3 & & 4 & $12(92 \%)$ \\
\hline viii & 3 & & 30 & $13(75 \%)^{\mathrm{c}}$ \\
\hline ix & 4 & $\mathrm{OH}$ & 2 & $6(81 \%)$ \\
\hline
\end{tabular}

${ }^{a}$ The glycosyl additions were all under a solvent-free condition with the presence of excessive alcohol nucleophile ( $>30$ equiv), except for the entry viii in which 3 equiv of the acceptor was dissolved in nitropropane (solvent).

${ }^{\mathrm{b}}$ All the reactions were carried out at $150{ }^{\circ} \mathrm{C}$ with $200 \mathrm{~W}$ of microwave energy.

${ }^{\mathrm{c}}$ In addition to the desired product, hydrolyzed product $14(10 \%)$ was observed. 
glycosides 6-13 in an open vessel. The CEM 'Discover' Focused Microwave ${ }^{\mathrm{TM}}$ Synthesis System is the instrument to provide microwave energy. Except for entry viii, all the reactions were studied under a solvent-free condition and the majority of the reactions were complete at $150{ }^{\circ} \mathrm{C}$ with $200 \mathrm{~W}$ of microwave energy within 4-8 min with $75-92 \%$ yield. No reaction was found for the reaction with 1,2:3,4-di- $O$-propylidene- $\alpha$-D-glucopyranoside in the absence of solvent. When nitropropane was used as the reaction solvent, the desired product was obtained in $75 \%$ yield with concomitant formation of the rearranged product $\mathbf{1 4}(10 \%$ yield, resulting from the addition of water). Because the reactions were carried out without cooling, the radiation energy declined to maintain the constant temperature during the microwave process. Therefore, the same reactor with simultaneous cooling is likely to finish reaction in a shorter time.
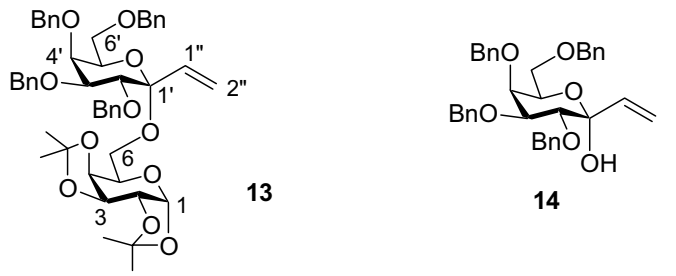

Consistent with our earlier work, ${ }^{11}$ the glycosylation reactions displayed exclusive stereoselectivity. All the reactions occurred via $\alpha$-glycosyl additions, that is, the nucleophilic attack from the bottom face of the sugar ring, to result in the vinyl group at the $\beta$-position. The product structures were either rigorously determined by DEPT, NOESY and other spectroscopic spectra, or in good agreement with the reported NMR spectral data. For example, the DEPT spectra of the glycosylation product 13 indicated the $\mathrm{C}-1^{\prime}$ resonance appeared at $\delta 99.96$, besides the other two quaternary carbons ( $\delta$
108.44 and 109.11) of the isopropylidene groups. The NOESY spectra of 13 (Fig. 2) exhibited the cross-peaks between $\mathrm{H}^{\prime}(\delta 4.16)$ and $\mathrm{H} 6 \mathrm{a}(\delta 3.50)$, as well as $\mathrm{H} 2^{\prime}(\delta$ $3.84)$ and $\mathrm{H}^{\prime \prime}(\delta 5.95)$, which thus verified that the $C$-vinyl group is located at the $\beta$-position. In addition, the three-bond carbon-proton coupling constant ${ }^{3} J_{\mathrm{C}, \mathrm{H}}$ $(\sim 1.6 \mathrm{~Hz})$, related to the orientation of the $\mathrm{H} 2^{\prime}$ and vinyl carbon $(-\mathrm{CH}=)$, also confirmed the expected stereochemical outcome. ${ }^{22}$

Despite the low stability, the phenyl-substituted exo-glycal $\mathbf{4}$ can be possibly used as the glycosyl donor providing that the compound is freshly made before the glycosylation. In the reaction with $n$-hexanol (entry ix), the formation of the desired product was finished within 2 min in $81 \%$ yield by the microwave method, in contrast to the $64 \%$ yield (plus $20 \%$ of an unknown product) obtained by the conventional heating at $100{ }^{\circ} \mathrm{C}$ for $30 \mathrm{~min}$. Consistent with the previous result, this comparison clearly indicates that the microwave irradiation has the advantages of shorter reaction time and cleaner reactions.

Additionally, there are a number of factors affecting the reactivity, as shown in Table 2. The glycosylation of exo-glycosyl acetate 2 (entries $\mathrm{i}$ and ii) took a longer time than that of $\mathbf{3}$, which echoes the previous result that $t$-butyl and phenyl carbonates have dissimilar rates. Interestingly the carbonate functionality exerts varied activity in exo-glycal, endo-glycal, and glycoside. endoGlycal $\mathbf{1 5}$ is less reactive than analogous exo-glycal 3, as indicated by the longer reaction time and incomplete reaction in entries iii, v, vi, and viii (in comparison with entries $\mathrm{i}-\mathrm{iv}$ of Table 1 , respectively), even though the latter molecule exhibits more steric hindrance. The formation of hydrolyzed product $\mathbf{2 1}$ was only observed for the microwave irradiation of $t$-butylcarbonyl $2,3,4,6-O$ tetrabenzyl- $\alpha$-D-galactoside 16, as shown in the parallel studies of entries $x$ and xi. The addition of Lewis acid

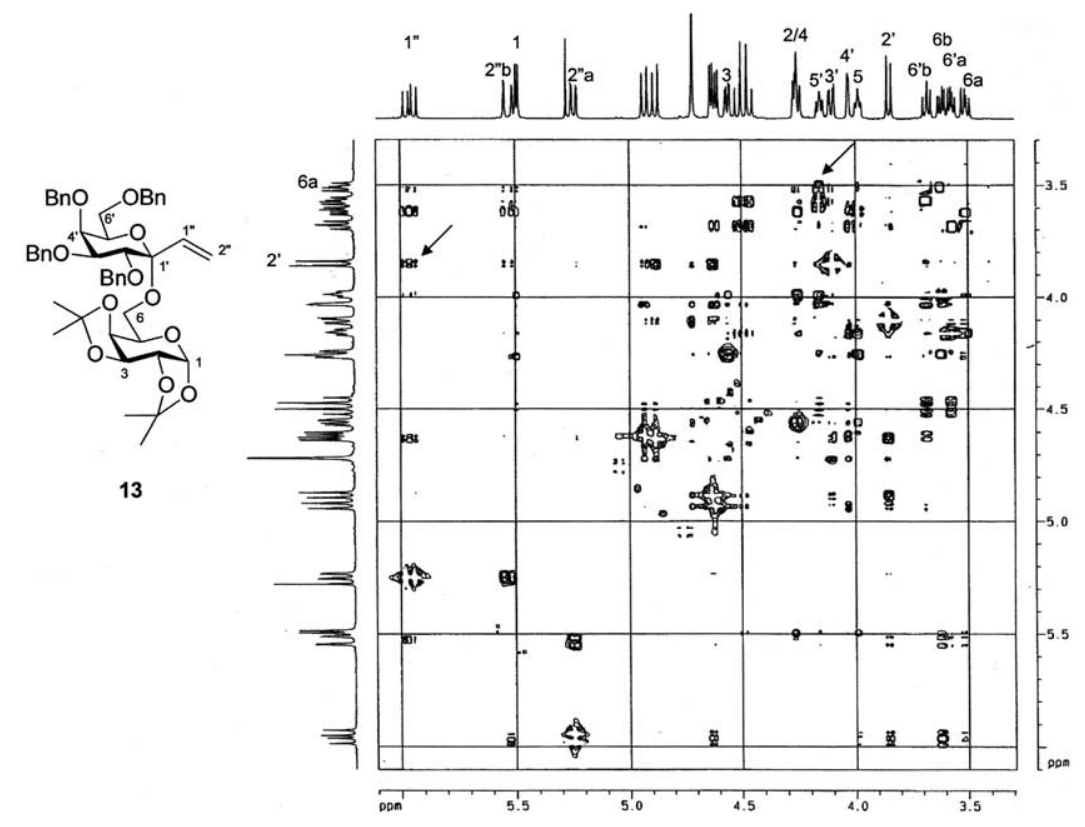

Figure 2. NOESY spectra of product 13. The arrows designate the cross-peaks between $\mathrm{H} 5^{\prime}$ and $\mathrm{H} 6 \mathrm{a}$, as well as $\mathrm{H} 2^{\prime}$ and $\mathrm{H} 1^{\prime \prime}$. 
Table 2. Glycosylation reactions of carbonate donors $\mathbf{2}, \mathbf{1 5}$, and $\mathbf{1 6}$
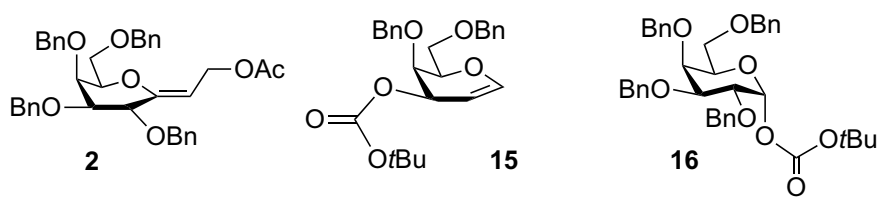

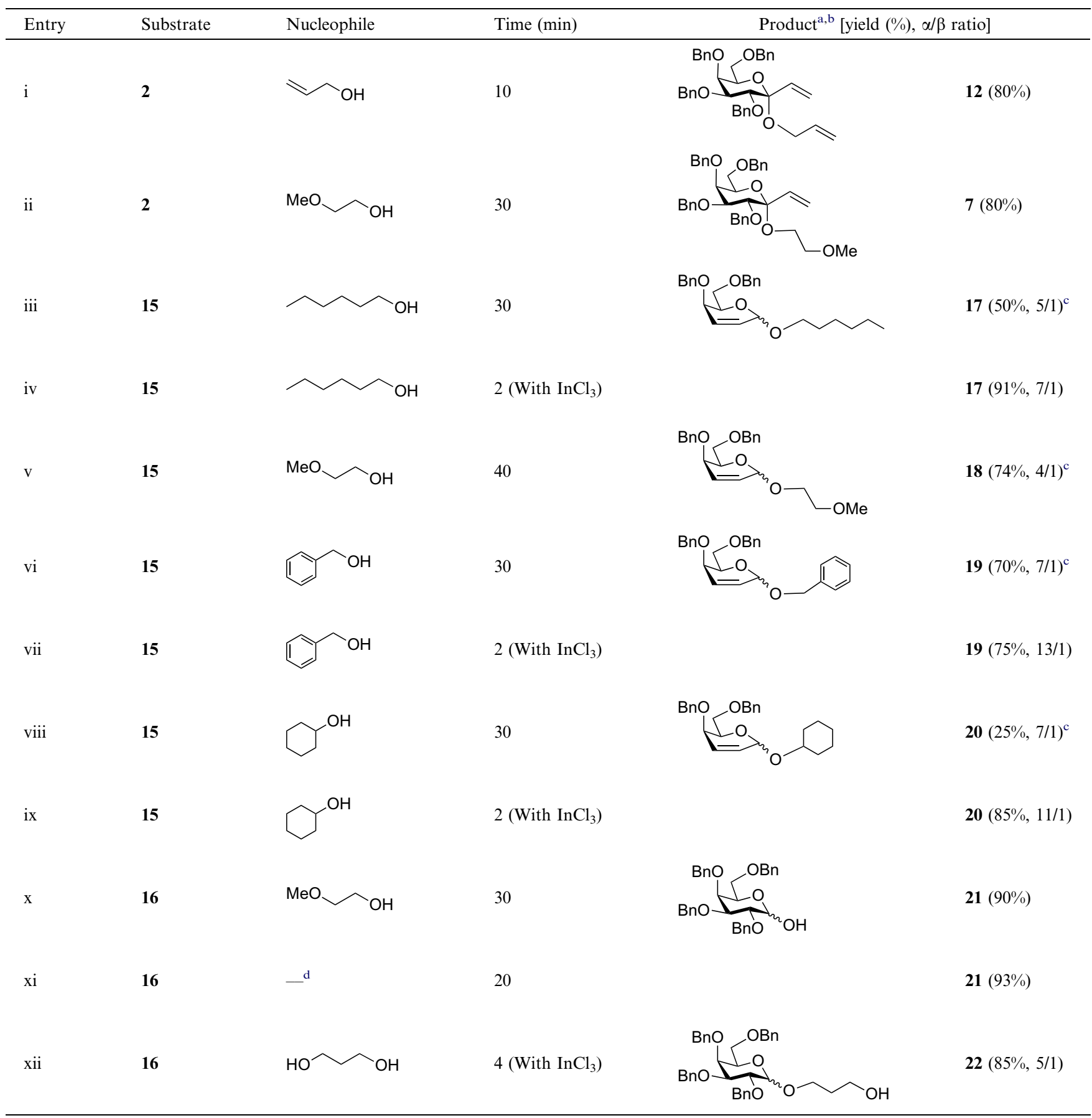

$\bar{a}$ All reactions were carried out at $150{ }^{\circ} \mathrm{C}$ with $200 \mathrm{~W}$ of microwave energy in a solvent-free condition with the alcohol acceptor in excess $(>30$ equiv), except for entry xi.

${ }^{\mathrm{b}}$ The $\alpha / \beta$ ratio was determined on the basis of ${ }^{1} \mathrm{H}$ NMR integration.

${ }^{\mathrm{c}}$ The reactions of entries iii, v, and viii were not complete with the remaining starting materials of $40 \%, 20 \%$, and $70 \%$, respectively.

${ }^{\mathrm{d}}$ DMF was the solvent.

will enhance the glycosylation activity. In the presence of $\mathrm{InCl}_{3}$ ( 0.2 equiv), for instance, the reaction of endoglycal 15 with $n$-hexanol (entry vi) was complete in
2 min to produce the desired glycoside $(91 \%) .{ }^{19}$ Similar improvements in the yield, reaction time and stereoselectivity were made in the case of benzyl alcohol (entry vii) 
and cyclohexanol (entry ix). ${ }^{23}$ This approach was also effective to the glycosyl addition of galactoside $\mathbf{1 6}$ (entry xii). As a consequence, the presence of Lewis acid is complementary to microwave-assisted glycosylation.

In summary, this report not only demonstrates the high efficiency of the microwave-induced glycosylation of exo-glycals, but also compares the activity among exo-glycals, endo-glycals and general glycosides. Further investigation to understand the basis underlying the rate difference is in progress and will be published in due course.

\section{Acknowledgements}

The authors thank the financial support from the National Science Council of Taiwan (NSC93-2113M-001-003 and NSC93-2113-M-001-034) and Academia Sinica, Taiwan.

\section{References}

1. Williams, L. J.; Garbaccio, R. M.; Danishefsky, S. J. In Carbohydrates in Chemistry and Biology; Ernst, B., Hart, G. W., Sinay, P., Eds.; Wiley-VCH Verlag GmbH: Weinheim, Germany, 2000; Vol. 1, pp 61-92.

2. Seeberger, P. H.; Danishefsky, S. J. Acc. Chem. Res. 1998, 31,685

3. Zheng, C.; Seeberger, P. H.; Danishefsky, S. J. Angew. Chem., Int. Ed. 1998, 37, 786; Goering, B. K. Ph.D. Dissertation, Cornell University, 1995.

4. Zheng, C.; Seeberger, P. H.; Danishefsky, S. J. J. Org. Chem. 1998, 63, 1126.

5. Seeberger, P. H.; Eckhardt, M.; Gutteridge, C. E.; Danishefsky, S. J. J. Am. Chem. Soc. 1997, 119, 10064.

6. Danishefsky, S.; Kato, N.; Askin, D.; Kerwin, J. F., Jr. J. Am. Chem. Soc. 1982, 104, 360.

7. Taillefumier, C.; Chapleur, Y. Chem. Rev. 2004, 104, $263-$ 292.

8. Yang, W.-B.; Chang, C.-F.; Wang, S.-H.; Teo, C.-F.; Lin, C.-H. Tetrahedron Lett. 2001, 42, 4657.

9. Yang, W.-B.; Wu, C.-Y.; Chang, C.-C.; Wang, S.-H.; Teo, C.-F.; Lin, C.-H. Tetrahedron Lett. 2001, 42, 6907.
10. Yang, W.-B.; Yang, Y.-Y.; Gu, Y.-F.; Wang, S.-H.; Chang, C.-C.; Lin, C.-H. J. Org. Chem. 2002, 67, 3773.

11. (a) Lin, H.-C.; Yang, W.-B.; Gu, Y.-F.; Chen, C.-Y.; Wu, C.-Y.; Lin, C.-H. Org. Lett. 2003, 5, 1087-1089; (b) Chang, C.-F.; Yang, W.-B.; Chang, C.-C.; Lin, C.-H. Tetrahedron Lett. 2002, 43, 6515.

12. Mukaiyama, T.; Sasaki, T.; Iwashita, E.; Matsubara, K. Chem. Lett. 1995, 455-456.

13. (a) Mukaiyama, T.; Miyazaki, K.; Uchiro, H. Chem. Lett. 1998, 635-636; (b) Mukaiyama, T.; Wakiyama, Y.; Miyazaki, K.; Takeuchi, K. Tetrahedron Lett. 1997, 38, 2943-2946.

14. Iimori, T.; Shibazaki, T.; Ikegami, S. Tetrahedron Lett. 1996, 37, 2267-2270.

15. Azumaya, I.; Niwa, T.; Kotani, M.; Iimori, T.; Ikegami, S. Tetrahedron Lett. 1999, 40, 4683-4686.

16. Cleophax, J.; Liagre, M.; Loupy, A.; Petit, A. Org. Process Res. Dev. 2000, 4, 498-504; Also see the comprehensive review: Perreux, L.; Loupy, A. In Microwaves in Organic Synthesis; Loupy, A., Ed.; Wiley-VCH Verlag $\mathrm{GmbH}$ : Weinheim, Germany, 2002; pp 76-110.

17. (a) Gedge, R. N.; Smith, F.; Westaway, K.; Ali, H.; Baldisera, L.; Laberage, L.; Rousell, J. Tetrahedron Lett. 1986, 27, 279-282; (b) Giguere, R. J.; Bray, T. L.; Duncan, S. M.; Majetich, G. Tetrahedron Lett. 1986, 27, 49454949.

18. Oliveiva, R. N.; Filho, J. R. F.; Srivastava, R. M. Tetrahedron Lett. 2002, 43, 2141-2143.

19. Das, S. K.; Reddy, K. A.; Roy, J. Synlett 2003, 1607 1610.

20. Mathew, F.; Jayaprakash, K. N.; Fraser-Reid, B.; Mathew, J.; Scicinski, J. Tetrahedron Lett. 2003, 44, 9051-9054.

21. Rannard, S. P.; Davis, N. J. Org. Lett. 1999, 1, 933-936.

22. (a) Tvaroska, I.; Taravel, F. R. Adv. Carbohydr. Chem. Biochem. 1995, 51, 15; (b) Li, X.; Ohtake, H.; Takahashi, H.; Ikegami, S. Tetrahedron 2001, 57, 4297; (c) Li, X.; Takahashi, H.; Ohtake, H.; Shiro, M.; Ikegami, S. Tetrahedron 2001, 57, 8053; (d) Schlesselmann, P.; Fritz, H.; Lehmann, J.; Uchiyama, T.; Brewer, C. F.; Hehre, E. J. Biochemistry 1982, 21, 6606.

23. The stereochemistry of compounds $\mathbf{1 7 - 2 0}$ was determined by the integration of the ${ }^{1} \mathrm{H}$ NMR spectra. In order for clear assignment, the $\alpha$-form (major) of $\mathbf{2 0}$ was hydrogenated to saturate the double bond at $25^{\circ} \mathrm{C}$ over $\mathrm{Pd} / \mathrm{C}$ in EtOAc containing $\mathrm{Et}_{3} \mathrm{~N}$. The resulting product $\mathbf{2 3}$ has the anomeric $\mathrm{H} 1$ resonance at $\delta$ 5.02. The small $J_{1,2}$ value $(3.0 \mathrm{~Hz})$ confirms the $\alpha$-configuration. 